\title{
MODERN ENDOVASCULAR TREATMENT METHODS FOR ERECTILE DYSFUNCTION: A CRITICAL ANALYSIS
}

DOI: 10.36740/WLek202009229

\author{
Magdalena Piegza' ${ }^{1}$, Mateusz Paterak ${ }^{2}$, Michał Błachut ${ }^{1}$, Jacek Piegza ${ }^{3}$ \\ ${ }^{1}$ CHAIR AND DEPARTMENT OF PSYCHIATRY IN TARNOWSKIE GORY, SCHOOL OF MEDICINE WITH THE DIVISION OF DENTISTRY IN ZABRZE, POLAND, \\ MEDICAL UNIVERSITY OF SILESIA IN KATOWICE, ZABRZE, POLAND \\ 2STUDENT SCIENTIFIC SOCIETY AT CHAIR AND DEPARTMENT OF PSYCHIATRY IN TARNOWSKIE GORY, SCHOOL OF MEDICINE WITH THE DIVISION OF \\ DENTISTRY IN ZABRZE, POLAND, MEDICAL UNIVERSITY OF SILESIA IN KATOWICE, ZABRZE, POLAND \\ 33RD CHAIR AND DEPARTMENT OF CARDIOLOGY, SCHOOL OF MEDICINE WITH THE DIVISION OF DENTISTRY IN ZABRZE, SILESIAN CENTER FOR HEART \\ DISEASES, POLAND, MEDICAL UNIVERSITY OF SILESIA IN KATOWICE, ZABRZE, POLAND
}

\begin{abstract}
$75 \%$ of men with coronary artery disease confirmed by coronarography have erectile dysfunction in history, while $75 \%$ of patients with a vascular etiology of ED have significant stenoses in penile arterial vascularization. Patients with coronary artery disease have shown a relationship between the range of the lesions in the coronary vessels and erectile dysfunction intensity.

This paper aims at attempting to systematize the knowledge of the benefits and drawbacks of nonsurgical endovascular treatment methods for erectile dysfunction with confirmed vascular causes. It analyzes seven studies which assess the results of erectile dysfunction treatment with percutaneous angioplasty. It also mentions the limitations of the cited works and formulates relevant conclusions.

Conclusions: The analysis shows that endovascular procedures in erection-related arteries are safe in a specially selected group of men. It is necessary to conduct further studies to define an appropriate group of patients who have a chance of benefiting optimally from the endovascular treatment of erectile dysfunction in a long-term follow-up.
\end{abstract}

KEY WORDS: atherosclerosis, angioplasty, erectile dysfunction, endovascular revascularization

Wiad Lek. 2020;73(9 p. II):2049-2055

\section{INTRODUCTION}

Valid medical classifications define erectile dysfunction (ED) as the inability to achieve or maintain an erection that is sufficient for a satisfactory sexual intercourse or the presence of at least one of the following symptoms in at least three-fourths of intercourse attempts: difficulty in achieving an erection during sexual activity, difficulty in maintaining the erection till its end or a pronounced loss of penile firmness during the erection. Both diagnostic systems (ICD-10 and DSM-5) require that those symptoms persist for at least six months [1]. This dysfunction is one of the most common sexological problems. Its probability increases with age: it affects $30.7 \%$ of men aged $57-64$, $44.6 \%$ of men aged $65-74$ and $43.5 \%$ of men aged $75-85$ [2]. ED is treated as an elevated risk marker for cardiovascular system diseases. $75 \%$ of men with coronary artery disease (CAD) confirmed by coronarography have ED in history [3].

Moreover, $75 \%$ of patients with a vascular etiology of ED have significant stenoses in penile arterial vascularization. The latter includes: the internal iliac artery, the internal pudental artery, the dorsal artery of penis and the cavernosal artery $[4,5]$. Furthermore, patients with CAD have shown a relationship between the range of the lesions in the coronary vessels and the intensity of ED symptoms [6].

Many factors suggest that endothelium damage may be the common pathophysiological mechanism behind CAD and ED. Consequently, a reduction of cardiovascular risk factors owing to lifestyle change and pharmacotherapy, described in a meta-analysis of 740 patients from six clinical trials conducted in four countries, significantly increased the IIEF- 5 (International Index of Erectile Function) score [7]. The International Index of Erectile Function (IIEF-5), colloquially called the erectile dysfunction questionnaire, is used to assess the presence and intensity of erectile dysfunction in the last six months and is constantly applied in clinical trials [8].

The vascular causes of erectile dysfunction often coexist with a weaker response to phosphodiesterase type 5 inhibitors (PDE5I). It is estimated to concern $50 \%$ of men with ED [9].

It has been proved that as many as $90 \%$ of patients with a weak response to PDE5I show significant atherosclerotic lesions which cause arterial insufficiency in angiography [10-12].

There was shown in some publications that arterial endovascular treatments could contribute to improvement in $63 \%-65 \%$ cases $[13,14]$. 
Table 1. The results of the described research studies.

\begin{tabular}{|c|c|c|c|c|c|c|}
\hline Study & Methods & Diagnostic method & Number of patients & $\begin{array}{l}\text { Improvement } \\
\text { rate } \%\end{array}$ & Restenosis rate $\%$ & Comments \\
\hline $\begin{array}{l}\text { Rogers et al. } \\
\text { ZEN Study }\end{array}$ & $\begin{array}{c}\text { DES } \\
\text { implantation } \\
\text { in pudendal } \\
\text { arteries }\end{array}$ & $\begin{array}{c}\text { IIEF-5 } \\
\text { Angiography }\end{array}$ & 30 & 59,3 & 34,4 & $\begin{array}{l}\text { Patients with } \\
\text { disseminated } \\
\text { lesions and long- } \\
\text { term ED were not } \\
\text { good candidates } \\
\text { for endovascular } \\
\text { treatment }\end{array}$ \\
\hline $\begin{array}{l}\text { Wang TD et al. } \\
\text { PERFECT -1 } \\
\text { STUDY }\end{array}$ & $\begin{array}{c}\text { Balloon } \\
\text { angioplasty of } \\
\text { penile arteries }\end{array}$ & IIEF-5 & 20 & 60 & - & $\begin{array}{l}\text { Smaller balloons were } \\
\text { indicated because } \\
\text { penile vessels were } \\
\text { prone to dissection }\end{array}$ \\
\hline $\begin{array}{l}\text { Wang TD et al. } \\
\text { PERFECT - } 2 \\
\text { STUDY }\end{array}$ & $\begin{array}{c}\text { Balloon } \\
\text { angioplasty of } \\
\text { penile arteries }\end{array}$ & IIEF-5 & 22 & 54,5 & 40 & - \\
\hline Gur S. et al. & $\begin{array}{c}\text { Stent } \\
\text { implantation } \\
\text { and } \\
\text { percutaneos } \\
\text { angioplasty }\end{array}$ & SHIM & 26 & 61 & - & - \\
\hline Mazo EBI et al. & $\begin{array}{l}\text { Administration } \\
\text { of PDE5I } \\
\text { (wardenafil) }\end{array}$ & IIEF-5 & 122 & 64 & - & $\begin{array}{l}63 \% \text { improvement } \\
\text { rate in arteriogenic ED }\end{array}$ \\
\hline
\end{tabular}

This paper aims at attempting to systematize the knowledge of the benefits and drawbacks of nonsurgical endovascular treatment methods for erectile dysfunction with confirmed vascular causes.

\section{REVIEW}

There are few studies available concerning the vascular diagnostics and nonsurgical intervention treatment of ED. The oldest one, the ZEN Study, aimed at assessing the safety and possibility of applying drug-eluting stent (DES) angioplasty in the treatment of selected patients with an atherosclerotic etiology of ED in the internal pudental artery (IPA). Out of 383 adult men, the researchers selected 30 sexually active men (one partner at the time of the study) with a suboptimal response to PDE5I, a decreased flow in the right and left cavernosal artery (Doppler ultrasonography - DUS) and a significant stenosis in one IPA or both IPAs (visible on an angiogram). The ED intervention treatment effectiveness was assessed using IIEF-5 and SEP (Sexual Encounter Profile). Having met the ultrasonographic and angiographic criteria, the patients underwent IPA stenting with DES. The following values of a significant IPA stenosis were adopted: unilateral $-\geq 70 \%$, bilateral $-\geq 50 \%$. IIEF- 5 was used five times. First, it was applied before and after a four-week preliminary period during which the patients had four sexual intercourses while taking PDE5I (a score of $\leq 21$ was the basis for diagnosing ED; only the patients with scores of $>6$ and $\leq 21$ were qualified for further screening). The subsequent measurements were carried out one month, three months and six months after IPA stenting. The results showed no unfavorable changes in the long-term follow-up. 45 stents were implanted in 30 patients. $59.3 \%$ of patients achieved an improvement which was measured using IIEF after three months (a score increase of $\geq 4$ ) and persisted till the next measurement (after six months). The flow in the cavernosal arteries significantly increased after six months in comparison with the result of the first measurement and the one carried out a month after the intervention. A restenosis, assessed in a follow-up angiographic examination as a stenosis which narrowed the vessel by $>50 \%$, occurred in $34.4 \%$ of the atherosclerotic lesions the patency of which had been restored. The authors reached a conclusion that the use of drug-eluting stents (DES) to treat ED with an atherosclerotic etiology was safe and effective provided that the patient group was appropriately selected. They also decided that patients with disseminated lesions and long-term ED were not good candidates for endovascular treatment. They postulated further research aimed at assessing the effectiveness of that treatment method in a long-term follow-up [15].

The next study was PERFECT 1, which attempted to assess the safety and effectiveness of balloon angioplasty in ED patients with an isolated stenosis in penile arteries (unilateral: $\geq 70 \%$, bilateral: $\geq 50 \%$ ). Out of 150 patients who had undergone a computer tomography examination of pelvic vessels, the researchers selected 25 with erectile dysfunction for invasive diagnostics. Twenty men from that group who met the angiographic criteria (a max. 30 $\mathrm{mm}$ long lesion in a vessel with a diameter of $\mathrm{min} .1 \mathrm{~mm}$ ) underwent balloon angioplasty without stents. The clinical 
improvement was assessed using IIEF-5 (four times). The men who obtained a score of 5-21 and had two intercourses per month with the same partner in three previous months were initially considered as leading an active sexual life despite ED. An IIEF-5 score of at least 22 after three and six months or an increase by at least 4 points in comparison with the previous score was classified as an indicator of clinical improvement. The greatest number of atherosclerotic lesions was identified in the common penile artery. No adverse events were recorded in the long-term follow-up. A symptomatic improvement was achieved in $75 \%, 65 \%$ and $60 \%$ of patients after one month, three months and six months respectively. The effect noted directly after the intervention was the best. An IIEF-5 score of at least 22 was recorded in $20 \%, 20 \%$ and $15 \%$ of patients respectively. Penile artery angioplasty as an ED treatment method in patients with an isolated stenosis in one or the same vessel proved safe and effective in $60 \%$ of patients. The authors recommended pelvic vessel angiography as a valuable examination in the precise imaging of the anatomy of atherosclerotic lesions in penile vessels. Additionally, smaller balloons were indicated because penile vessels were prone to dissection. That group of researchers also articulated the need for further studies assessing the effects of intervention treatment in a long-term perspective [16].

The PERFECT 2 Study assessed the safety and effectiveness of balloon angioplasty in ED patients with an isolated stenosis in penile arteries (unilateral: $\geq 70 \%$, bilateral: $\geq 50 \%$ ). Out of 150 men who had undergone pelvic vessel angiography and arteriography, the researchers selected 22 patients who met the angiographic criteria of inclusion in the study (a less than $40 \mathrm{~mm}$ long lesion in a vessel with a diameter of min. $1 \mathrm{~mm}$ ). They underwent balloon angioplasty without stents. The procedure was effective in $91 \%$ (31 out of 34) patients. No adverse events were recorded in the long-term follow-up. One year later, the clinical improvement persisted in a half of the patients. Eight months after the procedure, restenosis was identified in $40 \%$ of men [17]. The authors reckon that the described solution seems better for penile vascularization stenoses because their diameter is smaller than $2 \mathrm{~mm}$, thus excluding the use of stents. However, the $40 \%$ restenosis rate eight months after the procedure indicates the need to improve it further. Drug-coated balloons (DCB) seem a possible alternative in this case. They have been used in femoral-popliteal stenoses, yielding good results (low restenosis rates). Angioplasty is beneficial even if complicated by restenosis because the restenotic lesions measured in studies have proved shorter than the pre-angioplasty lesions, which facilitates reintervention [18].

In PERFECT 4 Study, $80 \%$ of patients immediately benefited from revascularization. A year later, however, a permanent improvement of erectile function was diagnosed only in $50-60 \%$ of the treated men. Consequently, a moderate success was recorded [19].

In the next study, von Allmen et al. [12] attempted to identify a specific pattern of damage to the arteries supplying the penis in ED patients with an incomplete response to PDE5I and CAD and/or coexisting cardiovascular risk factors in history. They examined 26 men (average age: 55) who had been sexually active with the same partner for over six months and had made four unsuccessful intercourse attempts in a month after taking PDE5I. The IIEF-5 score $(\leq 21)$ pointed at erectile dysfunction. The men underwent penile artery DUS with an alprostadil injection into the corpora cavernosa and an assessment of PSV (peak systolic velocity) and EDV (end-diastolic velocity). Based on digital subtraction angiography (DSA), two groups of arterial lesions were defined: 1) macroangiopathy $-a>70 \%$ stenosis in the internal iliac artery $(n=10)$, the common iliac artery $(n=2)$ or the internal pudental artery $(n=5)$, which was treated via angioplasty with stent implantation or only balloon angioplasty (in the IPA); and 2) microangiopathy (in seven patients) - lesions in smaller vessels than the internal pudental artery (penile arteries with a diameter of $<1 \mathrm{~mm}$ ), with no vascular intervention. Eight patients showed no lesions in the arteries supplying the penis. The angioplasty of erection-related arteries was performed according to the commonly known procedure algorithm for critical lower limb ischemia. Small vessel stenting was avoided. Angioplasty treated 17 lesions in 11 patients; only nine men repeated IIEF-5 six months later, but their results did not improve significantly. No statistically significant changes to PSV or EDV were recorded after six months in comparison with the first measurement. As the authors concluded, nearly $40 \%$ of patients were diagnosed with macroangiopathic lesions in erection-related arteries (those were effectively treated with angioplasty), while patients with microangiopathy showed predominantly atherosclerotic lesions in the vessels above the internal pudental artery (IPA). Like their predecessors, the authors suggested the application of more adequate diagnostic methods to select an appropriate group of patients who would benefit optimally from endovascular treatment [12].

An adequate pharmacotherapy is the standard procedure in ED (PDE5I, hormonal therapy) often in combination with psychotherapy. Injections of prostaglandins into the cavernosus bodies or urethral preparations are being used increasingly less often. Vascular interventions and penile protheses constitute the last stage of ED treatment.

The first step, even before endovascular interventions, is oral administration of PDE5I. This therapy is applied in all patients unless contraindications are present. It is relatively common that patients do not respond to treatment [11].

In relation to the above, a study was conducted to isolate groups which did not respond to PDE5I treatment. To achieve that, the researchers examined the relationship between the lesion diameter measurement results after a mechanical closure and restoration of the blood supply in the cavernosal arteries using a pressure cuff following vardenafil administration to ED patients.

The total vardenafil effectiveness in all the subjects reached $64 \%$. The best response was achieved in the groups of patients with psychogenic ED (78\%) and arteriogenic ED (63\%). Five out of 15 patients with neurogenic ID 
achieved a clinical improvement. Only the patients with arteriogenic ED showed a moderate positive correlation between PICAD (percent of increase of cavernosal artery diameter) following vardenafil administration and an IIEF score improvement [11].

The paper published by Swiss researchers in 2018 [17] concerned assessing the occurrence of an early elastic recoil in erection-related arteries among ED patients who underwent endovascular revascularization of the pudental artery or the penile arteries. The researchers examined 21 men insensitive to PDE5I: they excluded endocrine disorders and venous leak as ED causes and performed imaging angiography which confirmed the arteriogenic causes of the subjects' ED. The biggest number of atherosclerotic lesions was observed in pudental arteries $(n=27)$, while fewer of them were located in the common penile artery $(n=4)$. IIEF was applied before and three months after the procedure. The result obtained after three months was significantly better than the first one $(\mathrm{p}<0.001)$. Mild recoils $(10-30 \%)$ were treated with DCB angioplasty. If a recoil exceeded $30 \%$ ten minutes after the procedure, drug-eluting stents (DES) were applied. After the intervention, all the patients took tadalafil for three weeks (daily dose: $5 \mathrm{mg}$ ) as well as aspirin and clopidogrel for one year. The authors have concluded that endovascular therapy of arteriogenic ED is a promising treatment alternative in a considerable group of patients. However, pudental artery recoils are frequent and might contribute to restenosis later on. Consequently, further studies are necessary to find the ideal solution for avoiding restenosis in those small ED-related vessels [20].

The researchers demonstrated a frequent relationship between common iliac artery stenosis and ED. Another study, conducted by Turkish researchers and published in 2013 [18], aimed at assessing the erectile dysfunction frequency in men with common iliac artery (CIA) stenosis and the effect of its revascularization on erectile function improvement evaluated using SHIM (Sexual Health Inventory for Men). They performed a retrospective analysis of the endovascular treatment of 36 common iliac artery stenoses in $35 \mathrm{men}$. The patients were asked if they were still interested in sex and whether they were able to recall their erectile function after stent implantation in the iliac arteries. The study included patients with chronic symptomatic CIA occlusion. However, patients aged 70 and over, patients previously diagnosed with iliac artery stenosis, acute thromboembolism or dissection as well as patients who had undergone unsuccessful rechanneling were excluded from the study. The researchers also excluded three patients who had undergone unsuccessful reperfusion. To allow erectile dysfunction diagnosis and intensity assessment, the patients filled in the SHIM questionnaire before as well as one to six months after the procedure. The erectile function improvement or deterioration was assessed based on SHIM score changes in subsequent measurements. The average age of the patient population was $57 \pm 5$ (range: 42-67). The most frequent atherosclerosis risk factors were: smoking in history (86\%), diabetes $(37 \%)$, coronary artery disease (64\%), hypertension (44\%) and hyperlipid- emia (46\%). All the patients showed symptoms of chronic intermittent claudication. Occlusions and stenoses of the iliac arteries were effectively treated with stent implantation or percutaneous angioplasty. The average occlusion length was $59 \pm 41$ (range: 10-180) $\mathrm{mm}$. The impotence rate reached $74 \%$ (26 out of 35 ) before the procedure. In general, $16(61 \%)$ out of 26 patients reported an erectile function improvement after iliac artery rechanneling. According to SHIM, the improvement was complete in six patients (17\%), satisfactory in nine patients $(26 \%)$ and moderate in one patient $(3 \%)$. The rechanneling type, the patient's age and the occlusion length were related to ED improvement in a one-way analysis. However, those did not constitute independent factors of an erectile function improvement in a multivariate analysis. All the patients in the group with combined occlusions of the external iliac artery and the common iliac artery $(n=5)$ showed mild to severe impotence. Bilateral stenoses in the internal iliac artery (IIA) were rechanneled and ED was successfully treated in three of them. The two remaining patients also showed bilateral IIA occlusions: erectile dysfunction subsided in one of them and remained unchanged in the other. Operative and postoperative complications occurred in eight patients (23\%). Serious procedure-related complications included artery dissections which caused a significant stenosis or closure of the ipsilateral artery near the treated section $(n=3)$ and an internal iliac artery occlusion caused by common iliac stenting $(n=1)$. All the flow-limiting foci were effectively treated via endovascular reintervention [21].

The summary results of described research studies were shown in table 1.

\section{LIMITATIONS OF THE CITED WORKS}

Important limitations of all the abovementioned studies include: small study groups, lack of a control group and low-specificity noninvasive methods of assessing the clinical improvement. Only von Allmen et al. examined their patients after angioplasty using digital subtraction angiography (DSA), which is presently the gold standard in assessing penile vascularization lesions. Moreover, only single stenoses were revascularized in most studies, which does not answer the question about procedure effectiveness for total occlusions and long tandem stenoses. According to the authors of the PERFECT 1 Study, not all the patients underwent invasive angiography. Some of them underwent only a CT angiography of pelvis, which is a less precise examination. Consequently, the number of restenoses may have been overstated.

An analysis of the ZEN Study planning reveals several inconsistencies. After the four-week treatment with sildenafil, the patients who did not react to it or whose response was suboptimal were all qualified as nonresponding to treatment. The authors made a mistake by failing to describe the earlier outcomes of PDE5I treatment, so the picture of the response to the applied treatment was not reliable $[15,22]$. The decision to apply DES in the treated patients 
was made based on an assumption that the smaller vessels in the pudendal artery vascularization responded to zotarolimus as did the smaller coronary arteries and thus restenosis would be prevented. However, $34.4 \%$ (11 out of 32) of the rechanneled lesions were affected by restenosis, which is a considerable percentage compared to the average restenosis frequency in the coronary arteries (9.2\%). For unknown reasons, zotarolimus is less effective in the treatment of lesser pelvis arteries [22]. Balloon angioplasty in the PERFECT 2 Study yielded a $40 \%$ restenosis rate after eight months. That percentage is comparable with the rate obtained by the balloon angioplasty of popliteal arteries and most peripheral vessels [20]. The authors pointed at the possibility of improving those results by using DES, but the actual improvement rate was less than $6 \%$. A drawback of using DES is the necessity of double antiplatelet therapy, which was not mentioned in the ZEN Study. The risk-benefit ratio for the necessity of double antiplatelet therapy following DES implantation seems obvious in CAD treatment, but is doubtful when using DES to treat ED. Only pelvic vessels were stented in the ZEN Study. Penile vessels cannot be made patent using stents because their diameters are too small: the penile artery diameter is $<2$ $\mathrm{mm}$, while the smallest stent diameter available is $2.0 \mathrm{~mm}$, and excessive stretching of a vessel results in an intensified restenosis. The stent breakage risk during sexual activity must also be taken into account [20]. Moreover, the ZEN Study disqualified patients with coexisting venous drainage disturbances (EDV $>5 \mathrm{~cm} / \mathrm{s}$ ), therefore excluding a possible cause of the failure to obtain the anticipated effects of endovascular treatment.

One should mention that there is a specific group of patients who may benefit from this method of artery patency restoration in the lesser pelvis: young men after blunt traumas to the lesser pelvis. Arterosclerosis rarely is the cause of ED in 30- 40- year- old men. However, endovascular treatments could be useful in some circumstances. The stenosis development mechanism in this patient group is based on two phenomena. First, a trauma causes vascular endothelial dysfunction which drives the atherosclerotic process resulting in stenoses. The second phenomenon is of an anatomical origin: the distal IPA running through Alcock's canal is extremely exposed to a blunt trauma and the pressure exerted by the ischiopubic branch [22]. The method proposed in the ZEN Study may prove the perfect solution for treating difficult cases which feature focal atherosclerotic lesions caused by the trauma in question [22].

The significant limitations of the study conducted by von Allmen et al. include the presence of other, nonvascular factors influencing the erectile function: $46 \%$ of the patients were taking beta-blockers [12].

$60 \%$ patients in the study described by Turkish researchers noted an erectile function improvement following endovascular procedures [21]. Still, this study also has several limitations. First, it involved a small group which restricted the statistical analysis. Second, it seems that an ED assessment based only on a questionnaire, even an anonymous one, may be distorted by lack of consistency or honesty in the answers. Psychological and functional causes of erectile dysfunction cannot be reliably separated either. The use of preoperative and postoperative SHIM questionnaires did increase the value of that study, but combining such application of those questionnaires with an objective assessment of erection using PBI (penile brachial index), duplex ultrasonography or angiography may create a more precise method of examining the real effect of endovascular therapy on erectile function. The same objections concern the use of IIEF-5. On the other hand, endovascular rechanneling and stenting of CIA occlusions may be an effective therapy, particularly in order to maintain or improve erectile function. A return to normal sexual function may be achieved via endovascular therapy of the CIA in patients with impotence of a vascular origin, without any psychogenic factors affecting erection, with distal artery damage and without a coexisting distal obstructive disease in the pudental or penile arteries. An assessment of patients with Leriche syndrome or iliac artery aneurysms should include a detailed interview concerning sexual functions.

One must also mention the surgical treatment of the veno-occlusive mechanism insufficiency in the corpora cavernosa of the penis. The possibility of preventing blood outflow from the penis and therefore maintaining a satisfactory erection is as important as an appropriate blood inflow [22]. However, urologists commonly view venous leak as a sign and not a cause of erectile dysfunction [24]. This aspect of ED treatment goes beyond the scope of the present paper though.

\section{DISCUSSION}

Intervention treatment of erectile dysfunction consists in the application of an appropriate endovascular method depending on the vessel type undergoing revascularization. The most common methods include balloon angioplasty and angioplasty with stent implantation in the erection-related arteries, i.e. those which supply blood to the penis. This treatment method requires selecting an appropriate group of patients who meet specific qualification criteria. Patients with disseminated atherosclerotic lesions, difficult vascular access for anatomical reasons and fixed erectile dysfunction as well as the coexistence of other, hard-to-eliminate causes will not benefit from this treatment method. Few studies concerning vascular diagnostics and nonsurgical intervention treatment of erectile dysfunction in patients with an insufficient response to PDE5I have been published thus far. No serious adverse events were noted in long-term follow-ups: the method proved safe to those patients. Treatment effectiveness was assessed using standard forms, most often the International Index of Erectile Function. In some studies, nearly $60 \%$ of patients achieved an improvement as measured using that test several months after the procedure. However, the restenosis rate turned out to be higher than the one for coronary vessel patency restoration. No procedure standards have been prepared yet and it remains unclear 
who should perform the revascularization procedures in erection-related arteries: an angiologist, a vascular surgeon, a urologist or a radiologist. Unlike surgeries, endovascular procedures do not entail the risk of nerve damage, but they may lead to the formation of microthrombi in the rechanneled vessels. Taking into account both the benefits and limitations stemming from this modern treatment method, the authors of the present paper recommend caution and moderate optimism.

One must not forget other, nonvascular erection-affecting factors which coexist with vascular causes, e.g. taking specific drugs, endocrine disorders or psychogenic factors, which have an enormous influence on the assessment of clinical improvement. To assess the effectiveness of erectile dysfunction treatment in a special population of patients among the men encumbered with cardiovascular risk factors using this method in a long-term follow-up, it is necessary to conduct randomized studies on larger patient groups [25].

\section{CONCLUSIONS}

Peripheral vascular atherosclerosis plays a significant role in erectile dysfunction development. Endovascular procedures in erection-related arteries are safe in a specially selected group of men. It is necessary to conduct further studies to define an appropriate group of patients who have a chance of benefiting optimally from endovascular treatment in a long-term follow-up. It is also necessary to use more adequate tools to assess the clinical state.

\section{REFERENCES}

1. Lew-Starowicz M. Zaburzenia erekcji. In: Lew- Starowicz M, Lew -StarowiczZ, Skrzypulec-Plinta V (eds). Seksuologia. Warszawa: PZWL; 2017, pp. 260-261.

2. Lindau ST, Schumm LP, Laumann E0, Levinson W, O'Muircheartaigh CA, Waite LJ. A study of sexuality and health among older adults in the United States. N Engl J Med. 2007;357(8):762-774. doi: 10.1056/ NEJMoa067423.

3. Kloner RA, Mullin SH, Shook T, et al Erectile dysfunction in the cardiac patient: How common and should we treat? J Urology. 2003;170:46-50. doi:10.1097/01.ju.0000075055.34506.59.

4. Shishehbor MH, Philip F. Endovascular treatment for erectile dysfunction: an old paradigm revisited. J Am Coll Cardiol. 2012;60(25):2628-30.

5. Benaragama KS, Singh AA, Taj T, Hague J, Boyle JR, Richards T. Erectile Dysfunction in Peripheral Vascular Disease: Endovascular Revascularization as a Potential Therapeutic Target. Vasc Endovascular Surg. 2020 Aug 25; doi:10.1177/15385744420952923 [online ahead of print].

6. Greenstein A, Chen J, Miller H, Matzkin H, Villa Y, BrafZ. Does severity of ischemic coronary disease correlate with erectile function? Int J Impot Res. 1997;9(3):123-126. doi:10.1038/sj.ijir.3900282.

7. Gupta BP, Clifton MM, Prokop L, Nehra A, Kopecky SL. The effect of lifestyle modification and cardiovascular risk factor reduction on erectile dysfunction: A systematic review and meta-analysis. Arch Intern Med. 2011;171(20):1797-1803. doi:10.1001/archinternmed.2011.440.

8. Rosen RC, Althof SE, Giuliano F. Research instruments for the diagnosis and treatment of patients with erectile dysfunction. Urology. 2006;68(3):6-16. doi:10.1016/j.urology.2006.05.046.
9. Wespes E, Amar E, Hatzichristou D, Montorsi F, Pryor J, Vardi Y. Guidelines on erectile dysfunction. Eur Urol. 2002;41:1-5. doi:10.1016/s03022838(01)00008-2.

10. Rogers JH, KarimiH, Kao J, etal. Internal pudendal arterystenoses and erectile dysfunction: correlation with angiographic coronary artery disease. Catheter Cardiovasc Interv. 2010;76:882-887. doi:10.1002/ccd.22646.

11. Mazo EBI, Gamidov SI, Iremashvili VV. Does the clinical efficacy of vardenafil correlate with its effect on the endothelial function of cavernosal arteries? A pilot study. BJU Int. 2006; 98(5):1054-8. doi:10.1111/j.1464-410X.2006.06433.x.

12. von Allmen RS, Nguyen DP, Birkhäuser FD, Bednar R, Kammer R, Do DD, Diehm N. Lesion pattern in patients with erectile dysfunction of suspected arterial origin: an angiographic study. J Endovasc Ther. 2016;23(1):76-82. doi:10.1177/1526602815613789.

13. Doppalapudi SK, Wajswol E, Shukla PA, et al. Endovascular Therapy for Vasculogenic Erectile Dysfunction: A Systematic Review and Meta-Analysis of Arterial and Venous Therapies. J Vasc Interv Radiol. 2019;30(8):1251-1258.e2. doi:10.1016/j.jvir.2019.01.024.

14. Diehm N, Marggi S, Ueki Y, et al. Endovascular Therapy for Erectile Dysfunction-Who Benefits Most? Insights From a Single-Center Experience. J Endovasc Ther. 2019;26(2):181-190. doi:10.1177/1526602819829903.

15. Rogers JH, Goldstein I, Kandzari DE, et al. Zotarolimus-eluting peripheral stents for the treatment of erectile dysfunction in subjects with suboptimal response to phosphodiesterase -5 inhibitors. J Am Coll Cardiol. 2012;60(25):2618-27. doi:10.1016/j.jacc.2012.08.1016.

16. Wang TD, Lee WJ, Yang SC, et al. Safety and six-month durability of angioplasty for isolated penile artery stenoses in patients with erectile dysfunction: a first-in-man study. Eurolntervention. 2014;10(1):147-56. doi:10.4244/EIJV10I1A23.

17. Wang TD, Lee WJ, Yang SC, et al. Clinical and imaging outcomes up to 1 year following balloon angioplasty for isolated penile artery stenoses in patients with erectile dysfunction: The PERFECT - 2 study. J Endovasc Ther. 2016;23:867-877. doi:10.1177/1526602816669337.

18. Katsanos K, Spiliopoulos S, Paraskevopoulos I, Diamantopoulos A, Karnabatidis D. Systematic review and meta-analysis of randomized con- trolled trials of paclitaxel-coated balloon angioplasty in the femoropopliteal arteries: role of paclitaxel dose and bioavail- ability. J Endovasc Ther. 2016; 23:356-370. doi:10.1177/1526602815626557.

19. Wang TD, Lee WJ, Lin PC, et al. A randomized comparison between drug-eluting balloon and conventional balloon angioplasty for lesions in the penile artery in patients with erectile dysfunction: the PERFECT-4 study. Paper presented at: Euro PCR; May 17-20, 2016; Paris, France.

20. Diehm N, Do D-D, Keo H-H, et al. Early recoil after ballon angioplasty of erection - related arteries in patients with arteriogenic erectile dysfunction. J Endovasc. Ther. 2018;25(6):710-715. doi:10.1177/1526602818807704.

21. Gur S, Ozkan U, Onder H, Tekbas G, Oguzkurt L. The effect of endovascular revascularization of common iliac artery occlusions on erectile function. CardioVascular and Interventional Radiology. 2013;36(1):84-89. doi:10.1007/s00270-012-0359-3.

22. Kim ED, Owen RC, White GS, Elkelany 00, Rahnema CD. Endovascular treatment of vasculogenic erectile dysfunction. Asian J Androl. 2015;17(1):40-43. doi:10.4103/1008-682x.143752.

23. Spiliopoulos S, Diehm N. Commentary: Endovascular treatment of erectile dysfunction due to penile artery stenosis: balloon angioplasty of small-caliber vessels offers valid midterm outcomes.J Endovasc Ther. 2016;23(6):878-879. doi:10.1177/1526602816669457. 
24. Życzkowski M, Bogacki R, Nowakowski K, Paradysz A. Chirurgiczne metody leczenia zaburzeń erekcji. Seksuol Pol. 2014;12(1):36-42.

25. Baumann F, Hehli D, MakaloskiV, Schumacher M, Schönhofen H, Diehm N. Erectile dysfunction - overview from a cardiovascular perspective. Vasa. 2017;46:347353. doi:10.1024/0301-1526/a000627.

\section{ORCID and contributionship}

Magdalena Piegza - 0000-0002-8009-7118 A-B,D-F

Mateusz Paterak - 0000-0001-7843-6355 B,D-F

Michat Błachut - 0000-0002-4438-2376

Jacek Piegza - 0000-0002-7356-4769 A,D,F

\section{Conflict of interest}

Authors declare no conflict of interest

\section{CORRESPONDING AUTHOR}

\section{Mateusz Paterak}

Student Scientific Society at Chair and Department of Psychiatry in Tarnowskie Gory,

School of Medicine with the Division of Dentistry in Zabrze,

Medical University of Silesia in Katowice, Poland;

tel.: 886714761

e-mail:mateusz.paterak1@gmail.com

Received: 16.07 .2020

Accepted: 12.09 .2020 